\title{
Um ensaísta entusiasmado
}

\section{Adelia Bezerva de Meneses}

[...] os verdadeiros poetas, os criadores das antigas epopeias, não compuseram seus belos poemas como técnicos, porém como inspirados e possuídos [...]. Porque o poeta é um ser alado e sagrado, todo leveza, e somente capaz de compor quando saturado do deus e fora do juízo, e no ponto, até, em que perde de todo o senso. [...] É por inspiração divina, exclusivamente, que cada um faz tão bem o que faz [...]. (Platão, 1980)

SSAS palavras de Sócrates no Diálogo Ion de Platão poderiam servir de epígrafe a Escritores, gatos e teologia de Waldecy Tenório, coletânea de ensaios em que se articulam literatura e o que ele chama de "teologia". Sim, para o autor, os poetas e ficcionistas - mesmo os mais entranhadamente ateus - seriam, para se usar o termo platônico, "enthousiasmados" (etimologicamente: en + theós: com um deus dentro). Aqui radica um nó, a que eu retornarei mais adiante.

Antes, um elenco sucinto das principais questões afloradas ao longo dos ensaios que compõem a coletânea, como um leitmotiv: a via estética como experiência do sagrado; a arte como lugar epifânico; a ideia da teologia como a pergunta sobre o sentido último das coisas; e, sobretudo, o esforço pungente de aproximar literatura e teologia. E tudo isso numa prosa leve e limpa, uma escrita calorosa, de comunicação sem travas com o leitor, com a dose exata de humor a nos conduzir pelo cipoal de citações, o mesmo humor espontâneo que inventou a "mediação" divertida dos gatos para costurar os vários capítulos do livro - gatos que, como se sabe, desde o Egito Antigo, têm trânsito livre para a transcendência e habitam o imaginário e os telhados de vários escritores famosos.

E provindas de aficionados a gatos, ou não, há citações de autores (do quila- te de Octavio Paz, Baudelaire, Fernando Pessoa, Guimarães Rosa, Clarice Lispector etc.), comprobatórias de "hierofanias" nos textos literários, numerosíssimas, mas que acabam por nos conquistar por sua eficácia estética. Senão, vejamos: "Quem me dirá se no arquivo secreto de Deus / estão as letras do meu nome?" (J. L. Borges); "Nós gritamos SIM ao eterno" (Drummond); "Existirmos, a que será que se destina?" (Caetano Veloso); "Deus dói” (Unamuno); “Abre teus olhos, meu Deus / Come de mim a tua fome" (Hilda Hilst); "Tua ausencia me rodea como la cuerda a la garganta" (J. L. Borges). Ou ainda, de Baudelaire, sobre a Poesia: "uma exigência devastadora de Absoluto".

Mas não só de citações-testemunho e de reflexões teóricas se constrói esse livro: alguns de seus capítulos propõem análises literárias, sob a óptica da teologia (ou seria vice-versa: abordagens teológicas com um instrumental da literatura?), como é o caso do estudo sobre o Evangelho Segundo Jesus Cristo, em que se rastreia a tensão entre o Jesus e o Deus de Saramago, com indisfarçável simpatia pelo primeiro, o que faria o ficcionista entrar na categoria de "teólogo charlatão"; ou o capítulo sobre João Cabral, "teólogo inconfessável", por conta da mesma "tensão com a linguagem" que os místicos experimentam. Mas há 
também ensaios em que aflora a metodologia privilegiada de Waldecy Tenório: uma abordagem comparativa, aos pares, que revelará por vezes, insuspeitadas articulações. Freud, o grande destrinçador dos problemas da psique, dizia que quando um problema é grande, arranja-se um outro com o qual se lidar concomitantemente, à maneira como se quebra uma noz: se uma só é difícil de abrir, toma-se na mão uma segunda noz, e o processo se viabiliza... E assim são abordadas duplas: Thérèse de Lisieux / Mme. Bovary; Proust / Manuel Bandeira; Adélia Prado / Hilda Hilst; Teilhard de Chardin / Saint-Exupéry. À maneira de Plutarco, que inaugurou a Biografia Comparada, com suas Vidas paralelas, Waldecy aborda pares - às vezes, um ser real e um ser de ficção. Como o capítulo que o leitor começa a ler de sobrancelha franzida e acaba convencido (e divertido) pelo paralelo entre a vida daquela que se tornou a popular "Santa Terezinha" e a biografia imaginária da personagem Mme. Bovary de Flaubert. Aí ele coteja as leituras que ambas fizeram, os contextos, os percursos, as experiências ("coincidência de formação", como ele diz) - para concluir, finalmente, que elas têm muito a ver entre si, mulheres que falam a linguagem amorosa.

Mas a questão realmente complicada diz respeito àquilo com que iniciei o meu texto, e que, embora diversamente nomeada ao longo de todo o livro, concentra-se especialmente em dois capítulos, o "O autor invisível" e "O teólogo charlatão". No primeiro deles, coloca-se uma questão que atormenta Clarice Lispector: "Falo como se alguém falasse por mim". O comentário vem na frase contígua: "o inconsciente, o superego?". Mas essa réplica em forma de interrogação vem apenas para ser descartada, pois na sequência ergue-se uma outra pergunta, dessa vez com a assinatura de Octavio Paz: "Como se chama, quem é esse que interrompe o meu discurso e me faz dizer coisas que não pretendia dizer"? (em El arco y la lira). E aí a resposta vem célere, por parte de Waldecy, infelizmente rápido demais encerrando o caso: "É Javé, o deus da Bíblia" (p.46). E o que se seguirá serão exemplos de passagens em que "Javé" se infiltrará na escrita de escritores tão diferentes como Dostoiévsky e Adélia Prado, ou Beckett e Cortázar.

A se aceitar tal afirmação, como ficariam, por exemplo, o poeta sufi Rumi, que o autor evoca mais adiante? $\mathrm{E}$ os gregos (não me refiro aos citados Zeus ou Atena, do Panteão olímpico, mas aos órficos, ao Deus de Platão, que no Timen leva o Caos a um Cosmos), ou os hindus, ou escritores de outras paragens, que não do mundo judaico-cristão? E os ateus militantes, não se sentiriam desrespeitados com a autoria de seus textos atribuída ao Deus do Antigo Testamento? De fato isso significaria confessionalizar uma voz que em outro momento do texto o autor vai equiparar à voz de Shiva, Krishna, Maomé, Iemanjá, Tupã, Xangô, Oxalá - declarando com muita pertinência que "Essa Teologia plural aprendeu que Deus muda como o fogo quando misturado com fragrâncias e é nomeado segundo o perfume de cada uma". Talvez aqui, num afã de comunicar-se com o seu público, o autor tenha adiado cavoucar um pouco mais esse chão. Teria sido melhor ficar com a Kristeva, citada ao fim do livro, quando se volta o assunto, e que alude "a um outro que existe em mim, ou ainda um não sei quê de exterior a mim mesmo que se ex- 


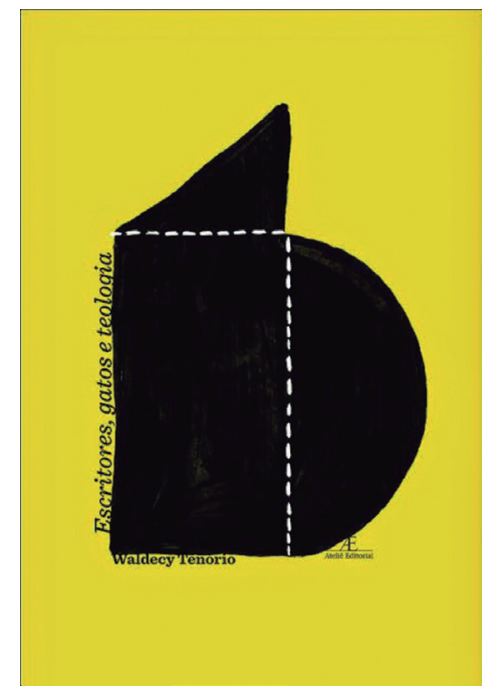

TENÓRIO, W. Escritores, gatos, teologia.

São Paulo: Ateliê Editorial, 2014.

prime através de minha boca em virtude de qualquer processo ainda inexplicado" (p.166). Ou com Greimas, que diz na mesma página: "Talvez exista um mistério na linguagem".

Mesmo quem perceba na Arte uma manifestação da transcendência, onde se expressam coisas a despeito do próprio autor, não poderia concordar com a visão da psicanálise, de que o poeta mantém aberto o canal de comunicação com o inconsciente - pessoal ou filogenético? Haveria que se levar em conta a arte como uma "formação contraideológica" - mas, advirto, tomo aqui "ideologia" na acepção quase caseira de "visão de mundo". Efetivamente, nos grandes poetas, é o que escapa ao espartilho ideológico que faz o encanto e a força de sua criação. Como aponta Alfredo Bosi (1977) no episódio de Paolo e Francesca da Rimini, na Divina comédia, em que a teologia de Dante cede à compaixão do poeta e ele colocará o casal adúltero no Inferno, sim, mas ... juntos por toda eternidade, na amada presença um do outro! Além, é claro, de, para interrogá-los, ter-lhes suspendido o castigo que deveria ser ininterrupto.

Voltando ao texto de Waldecy: o "autor invisível" aqui seria então o que comete a transgressão à ortodoxia teológica, que previa a pena infindável. Mas na realidade, o próprio autor, em outro momento do seu livro, está consciente disso, quando, por exemplo, endossa Casais Monteiro dizendo que "A poesia de Dante é imortal, sua teologia não é".

Um último topos resta a ser trabalhado: a questão do termo "teologia" usado no título, que, se etimologicamente diz respeito a "saber sobre Deus", no uso comum se reveste de uma dimensão inescapavelmente doutrinal e dogmática. Daí que Waldecy tenha tido que chamar de "teólogos charlatães" aqueles que estão à revelia do espartilho doutrinal. (Por que então não substituir de vez o termo "teologia" por algo como "experiência do sagrado"?) É certo que o autor nos adverte de que não se trata aqui de uma teologia "enrijecida em certezas, clericalismo ou intolerâncias", mas sim de "uma teologia marcada por um sentido profundo de hierofania, como a poesia de William Blake, revelando o caráter sagrado de todas as coisas" (p.20). Mas mesmo essa advertência não confortará o leitor arisco, lembrado de Inquisições e, mais na contemporaneidade, de congregações para as doutrinas corretas.

E é assim que o senso comum vê a palavra, no seu lado negativo. E nessa linha foi concebida a capa do livro, uma expressiva criação de Gustavo Piqueira, e que ganhou um prêmio importante, o "International Design Award". Pois bem, a capa mostra uma compacta figura negra, evocando ao mesmo tem- 
po um desenho de gato desses que as crianças fazem (basicamente, um círculo encimado por dois circunflexos paralelos - as orelhas); um Livro, recortado por um leve pontilhado em branco, as páginas semiabertas; e o negror rotundo de uma eventual batina eclesiástica (ou veste rabínica). Expressivo dessa concepção de “Teologia” cujos riscos venho apontando, mas que deixa no escuro literalmente - os momentos luminosos do livro, em que se pode vislumbrar a sobreposição da experiência poética com a experiência mística; e o entusiasmo do ensaísta.

\section{Referências}

BOSI, A. O Encontro dos tempos. In: O ser e o tempo da poesia. São Paulo:

Cultrix, 1977.

PLATÃO. Íon, In: Diálogos. Trad. Carlos Alberto Nunes. Belém: Universidade Estadual do Pará, 1980. v. I-II.

Adélia Bezerra de Meneses é doutora em Teoria Literária e Literatura Comparada pela USP. Foi docente de Literatura Brasileira no Leitorado de Romanística da Technische Universität de Berlim, professora de Teoria Literária e Literatura Comparada na USP e na Unicamp, onde se aposentou. @-adeliabm@terra.com.br

I Faculdade de Filosofia, Letras e Ciências Humanas, Universidade de São Paulo, São Paulo/São Paulo, Brasil. 